\title{
NUMERICAL ANALYSIS OF ENERGY ABSORPTION BY SANDWICH PANELS ON THE ARAMID FIBER BACKING
}

\author{
M. Bocian*, K. Jamroziak ${ }^{* *}$, D. Pyka ${ }^{* * *}$, E. Babej ${ }^{* * * * *}$
}

\begin{abstract}
The work concerns the analysis of a material solution on an aramid laminate reinforced with additional composite layers loaded with ballistic impact from the $7.62 \mathrm{~mm} \mathrm{M43} \mathrm{Full} \mathrm{Metal} \mathrm{Jacket} \mathrm{(FMJ).}$ The aim of the study is to identify alternative material systems to the reference $4 \mathrm{~mm}$ thick Armox A500T armored steel solution. The research was carried out using the finite element method with the application of the ABAQUS program. The optimal solutions for individual material systems were generated based on numerical analyses, thereby classifying them according to the mass-efficiency criterion. The numerical results obtained were validated in a ballistic experiment on samples made according to the methodology adopted for modeling. The range of absorbed energy and residual energy was determined for material systems based on the assumptions of the Recht-Ipson model.
\end{abstract}

Keywords: Numerical analysis, Ballistic shields, Aramid laminates, Impact, Small-caliber projectile.

\section{Introduction}

The progress of modern material engineering refers to the search for new material solutions characterized by better properties than currently used materials (Hanzell, 2016). Various material models, the verification of which is based on the determination of velocity V50 (Yahaya et al., 2016), are assumed as the basic parameter for the assessment of the ballistic capabilities of the shield. For this purpose, numerical tools prove very helpful, since their use makes it possible to verify the physical sense of the process of projectile piercing with ballistic velocities (Mazurkiewicz et al., 2015 and Pyka et al., 2017). The use of numerical methods requires an appropriate description of material properties (Mazurkiewicz et al., 2013) and the mathematical model assumed (Chai et al., 2018), which should take account of the nature and extent of damage (Kurzawa et al., 2017B) and the projectile core shape (Bandaru et al., 2015) as well as the structure of individual material layers (Kurzawa et al., 2017A). Therefore, it seems important to study the determination of material constants and their numerical representation in order to properly validate the adopted mathematical models of the shield and projectile material, as well as to evaluate the deformation of the projectile - shield system (Lenihan et al., 2018).

The following study focuses on the analysis of the ballistic shield resistant to firing with the $7.62 \times 39 \mathrm{~mm}$ (M43) steel core projectile (PS) shot from the $7.62 \mathrm{~mm}$ AKM rifles. This type of projectile is effectively stopped by a $4 \mathrm{~mm}$ ballistic steel shield. The task was to select alternative solutions based on composite materials reinforced with various additives. Numerous solutions based on numerical and experimental methods can be found in the literature. Nevertheless, the following evolution in materials engineering is a

\footnotetext{
Assis. Prof. Miroslaw Bocian, D.Sc., Ing.: Department of Mechanics, Materials Science and Engineering, Wroclaw University of Science and Technology, Smoluchowskiego 25; 50-372, Wroclaw; PL, miroslaw.bocian@pwr.edu.pl

** $\quad$ Assoc. Prof. Krzysztof Jamroziak, D.Sc., Ing.: Department of Mechanics, Materials Science and Engineering, Wroclaw University of Science and Technology, Smoluchowskiego 25; 50-372, Wroclaw; PL, krzysztof.jamroziak@ pwr.edu.pl

**** MSc., Eng. Dariusz Pyka: Department of Mechanics, Materials Science and Engineering, Wroclaw University of Science and Technology, Smoluchowskiego 25; 50-372, Wroclaw; PL, dariusz.pyka@pwr.edu.pl

**** Eng. Eryk Babej: Department of Mechanics, Materials Science and Engineering, Wroclaw University of Science and Technology, Smoluchowskiego 25; 50-372, Wroclaw; PL, eryk.babej@ gmail.com
} 
challenge for the research team to further search for optimal solutions implemented by the finite element method.

\section{Model and assumptions}

Several material layouts on a ballistic laminate underlay made of $5 \mathrm{~mm}$ thick Twaron ${ }^{\circledR} \mathrm{T} 750$ aramid fabric (LIM 3 (Jamroziak et al., 2012)) were accepted for testing. In the first variant, the ballistic laminate was reinforced with a layer of steel balls with a diameter of $6 \mathrm{~mm}$, and covered with polyurethane resin. The second variant was made with the laminate reinforced with $6 \mathrm{~mm}$ thick $\mathrm{Al}_{2} \mathrm{O}_{3}$ ceramics (Table 1). Additionally, a tin alloy in a honeycomb was applied as the reinforcement for the sample surface. The reference sample (S0) made of $4 \mathrm{~mm}$ thick Armox A500T armored steel $(400 \times 300 \mathrm{~mm})$ was used as a starting point for the planned tests.

Table 1: Material characteristics of the samples adopted for testing.

\begin{tabular}{|c|c|c|c|c|c|c|}
\hline No. & $\begin{array}{l}\text { Backing } \\
\text { (spall liner) }\end{array}$ & Reinforcement & $\begin{array}{l}\text { Number } \\
\text { of layers }\end{array}$ & $\begin{array}{l}\text { Dimensions of } \\
\text { reinforcing elements } \\
{[\mathrm{mm}]}\end{array}$ & $\begin{array}{l}\text { Mass } \\
{[\mathrm{g}]}\end{array}$ & $\begin{array}{l}\text { Density } \\
{\left[\mathrm{g} / \mathrm{cm}^{3}\right]}\end{array}$ \\
\hline S1 & \multirow{5}{*}{ 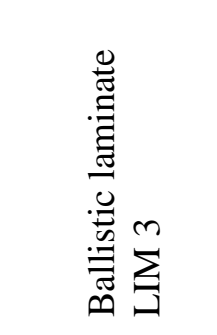 } & Tin alloy & 1 & $\phi 0.5$ & 41 & $7.3 / 11.3$ \\
\hline $\mathrm{S} 2$ & & Ceramic tiles & 1 & $51.8 \times 31.7 \times 6$ & 197 & 3.6 \\
\hline S3 & & Ceramic tiles & 2 & $51.8 \times 31.7 \times 6$ & 394 & 3.6 \\
\hline $\mathrm{S} 4$ & & Steel balls & 1 & $\phi 6$ & 150 & 7.8 \\
\hline S5 & & Steel balls & 2 & $\phi 6$ & 300 & 7.8 \\
\hline
\end{tabular}

Numerical models (Fig. 1) were made based on geometric models of the tested samples. The laminate used as backing consisting of 8 layers of aramid fabric on a neoprene matrix was homogenized in a twostage process (Pyka et al., 2017) adopting Representative Volume Element (RVE) for simulation (Fig. 1d). The reinforcement layer (steel balls and ceramics as well as tin alloy) was described with tetra-type solid elements (Fig. 1c-d). Simplification of the projectile model was achieved through modelling only the core (Fig. 1a) because the projectile jacket and lead jacket have a minimal effect on the result of the analysis and can be omitted (Fig. 1b). The size of the mesh elements was selected in such a way that their number did not significantly slow down the calculations and, on the other hand, enabled precise mapping of the geometry of the objects and hence obtaining accurate results. Additionally, the net was thickened around the model zones that are susceptible to significant deformations (a point of the projectile impact) in order to reduce the number of elements in the models. The element size was set at $0.1 \mathrm{~mm}$.

(a)

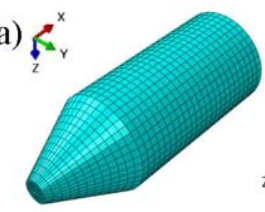

(b)

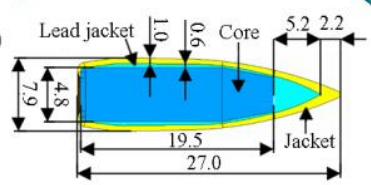

(c)
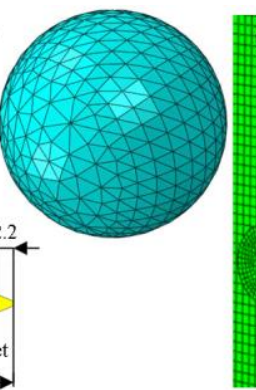
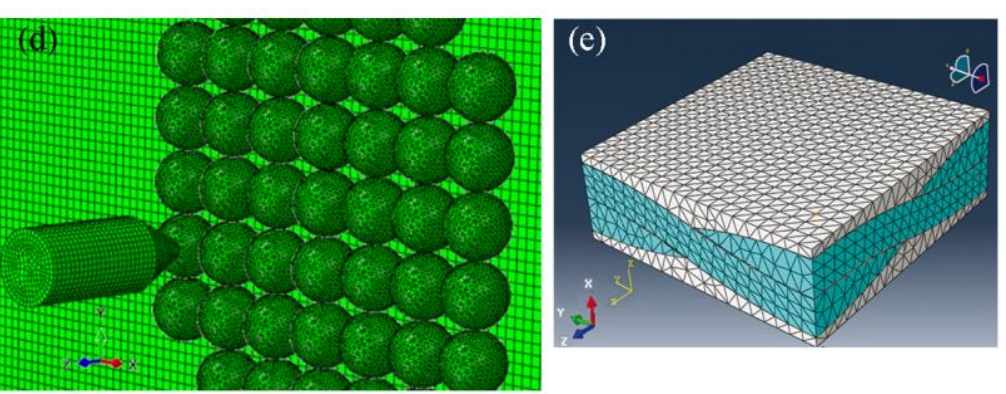

Fig. 1: Numerical models: $a$-core of the projectile, $b$-section of the M43 projectile, $c$-steel ball, $d$-model of the system with steel balls, $e-R V E$.

The constitutive Johnson-Cook model (J-C) was used to describe the material of the shield and the projectile. This model correctly represents the behavior of the material under conditions of high rate of deformation in the elastic-plastic range, with the reinforcement of the material and thermal weakening taken into consideration (Hanzell, 2016 and K1lic et al., 2013). In numerical calculations, the following material constants were assumed based on the authors' earlier works (Kurzawa et al., 2017B and Pyka et al., 2017) (Table 2). The boundary conditions were set in such a way that the numerical model reflected the features of the system as much as possible during experimental research. The projectile was assigned 
the initial velocity of $v_{0}=715 \mathrm{~m} / \mathrm{s}$. The rotational speed was omitted since its influence on kinetic energy dissipation is negligible. The ballistic shield was fixed along the perimeter. The restraint of the shield was blocked as translations and rotations in the three $X, Y$ and $Z$ axes. The default contact model based on the "penalty function" method was applied in analyses (Mazurkiewicz et al., 2015).

Table2: Material constants adopted for modelling according to the J-C model.

\begin{tabular}{llllllll}
\hline \multirow{2}{*}{ Material } & \multicolumn{7}{c}{ Material data } \\
\cline { 2 - 8 } & $\rho\left[\mathrm{g} / \mathrm{cm}^{3}\right]$ & $E[\mathrm{Gpa}]$ & $v[-]$ & $A[\mathrm{Gpa}]$ & $B[\mathrm{Gpa}]$ & $n[-]$ & $m[-]$ \\
\hline Ceramics & 3.60 & 360 & 0.15 & 0.40 & 0.50 & 0.1 & 1.0 \\
\hline LIM 3 Laminate & 1.44 & 7.50 & 0.30 & 1.50 & 1.51 & 0.2 & 1.0 \\
\hline A500T Armor steel & 7.80 & 210 & 0.33 & 0.81 & 1.65 & 0.1 & 1.0 \\
\hline
\end{tabular}

Where: $\rho$ - density, $E$ - Young's modulus, $v$ - Poisson's ratio, $A-$ yield at zero plastic strain, $B$ - hardening constant, $n-$ hardening exponent, $m$ - temperature softening constant.

\section{Tests and results}

Numerical simulations were performed in the ABAQUS program using the finite element method (FEM). The analyses covered the reference S0 sample and the S1-S5 samples made according to the specifications listed in Table 1 . The results obtained from numerical simulations were verified on the ballistic trajectory. The shooting was performed with the AK-47 using FMJ $7.62 \times 39 \mathrm{~mm}$ ammunition with PS projectile, taking into account the guidelines of PN EN 1522 standard (Accordance with the Europen Standard EN 1522:1998). The basic parameters of firing were recorded by the Doppler radar, based on which the average shot-through rate of $719 \mathrm{~m} / \mathrm{s}$ was determined. The shot S0 sample stopped the projectile. The S2 and S3 samples also demonstrated excellent projectile retention parameters. As for the S4 and S5 samples, a partial puncture was found in them. However, the puncture had no effect on the perforation of the witness plate in the S5 sample. The S1 sample turned out to be the worst and was rejected in further analyses. Experimental and numerical results were compared. Figure 2 compares kinetic energy as a function of time and the diagram (Fig. 3) displays the energy dispersed by individual samples. The results obtained from FEM are entirely consistent with the experimental ones, which proves the correct selection of material constants as well as starting and boundary conditions of the simulation.

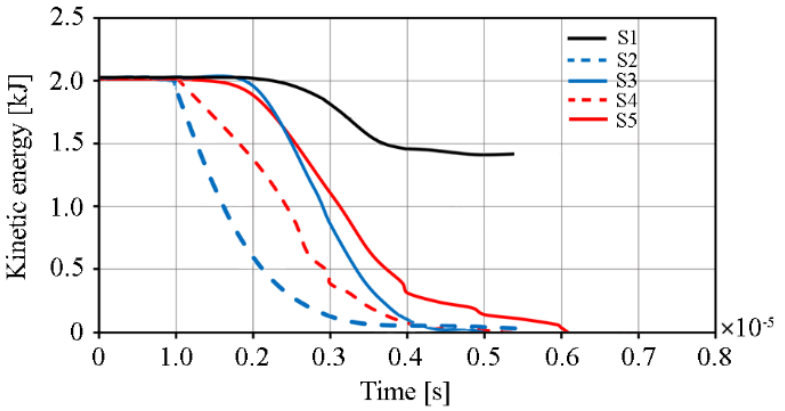

Fig. 2: The absorption of impact energy in the analyzed numerical models.

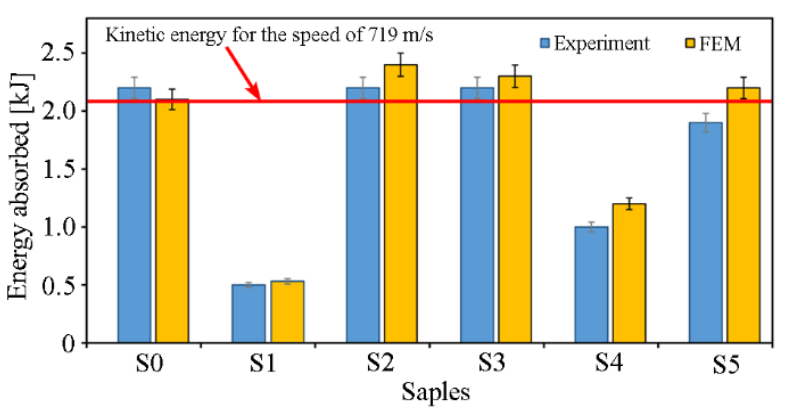

Fig. 3: Histogram of energy absorbed by individual samples.

In the following part of the analyses, the ballistic limit (Fig. 4) was evaluated on the basis of the RechtIpson model (Hanzell, 2016) and the mass efficiency of individual ballistic shields was compared (Fig. 5). The base parameter was assumed to be 1.0 (the S0 sample). The indicator smaller than the base parameter was the expected value, while above the base parameter - an undesirable value.

\section{Conclusion}

The presented results of the FEM analysis differ slightly from those obtained in the ballistic experiment, which can be seen in Figure 3. The S4 and S5 samples are a good example, as their efficiency was proven in the simulation, while during the shooting they were partially perforated. It was noted that the inertia force caused the reinforcement made of steel balls to break away earlier. Hence the proposal to close this 
surface with a thin aluminum layer which will make the system work under impact load, i.e., the hard layer should cause a change in the angle of impact in relation to the normal contact of the core with the shield and its ricocheting or blunting. The S2 and S3 samples reinforced with corundum ceramics confirmed their dissipation capacity in the experiment and the numerical simulation. The proposal to strengthen the LIM 3 ballistic underlay with elements of tin alloy turned out to be incorrect. Thus, further work will consider the technological change related to reinforcing the LIM 3 laminate with a layer of steel balls.

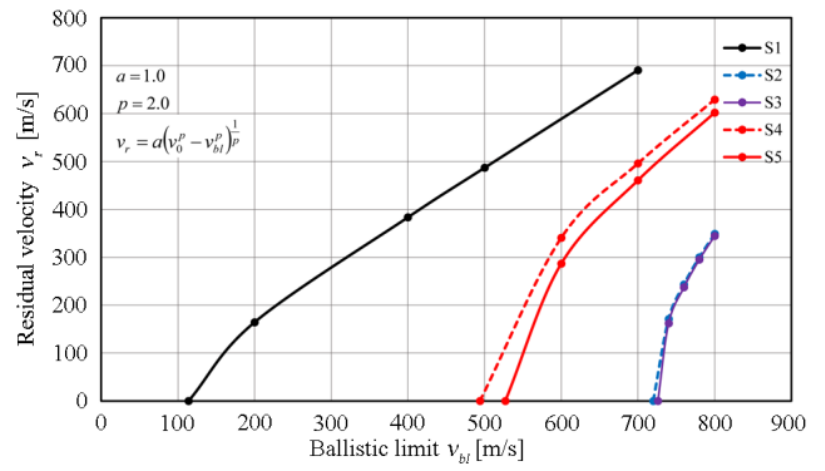

Fig. 4: The ballistic limit velocity of the projectile.

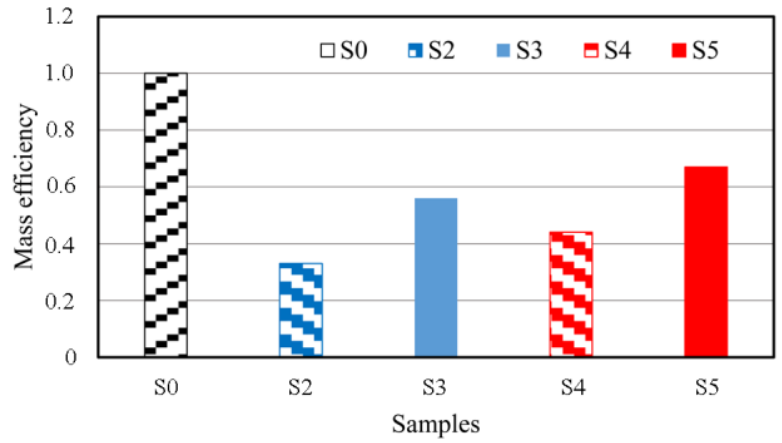

Fig. 5: Mass comparison of individual samples.

\section{Acknowledgement}

Calculations have been carried out in Wroclaw Centre for Networking and Super-computing (http://www.wcss.pl), grant No. 452

\section{References}

Bandaru, K.A. and Ahmad, S. (2015) Effect of projectile geometry on the deformation behavior of kevlar composite armors under ballistic impact. International Journal of Applied Mechanics, 7, 3, pp 1550039(23).

Chai, G.B., Manikandan. P. and Li, X. (2018) A numerical study on high velocity impact behavior of titanium based fiber metal laminates. Journal of Composite Science, 2(4), 62, doi.org/10.3390/jcs2040062.

Hazell, P.J. (2016) Armour: Materials, theory and design. CRC Press Taylor \& Francis Group, Boca Raton.

Jamroziak, K., Koziolek, S. and Smolnicki, T. (2012) Analysis of punching process of ballistic shield with the use of finite element method. Journal of Science of the Gen. Tadeusz Kosciuszko Military Academy of Land Forces, 165, pp 289-302, (in Polish).

Kilic, N. and Ekici, B. (2013) Ballistic resistance of high hardness armor steels against $7.62 \mathrm{~mm}$ armor piercing ammunition. Materials and Desing, 44, pp 35-48.

Kurzawa, A., Pyka, D., Pacha, J., Jamroziak, K. and Bocian, M. (2017) Numerical modeling of the microstructure of ceramic-metallic materials. Procedia Engineeria, 199, pp 1459-1500.

Kurzawa, A., Bocian, M., Jamroziak, K. and Pyka, D. (2017) Analysis of ceramic-metallic composites of ballistic resistance on shots by $5.56 \mathrm{~mm}$ ammunition. In: Proc. 23rd Int. Conf. on Engineering Mechanics, (Fuis, V. ed). Brno University of Technology, Brno, pp 574-577.

Lenihan, D., Ronan, W., O'Donoghue, P.E. and Leen, S.B. (2018) A review of the integrity of metallic vehicle armour to projectile attack. Proceedings of the Institution of Mechanical Engineers, Part L: Journal of Materials: Design and Applications, 233, 1, pp 73-94.

Mazurkiewicz, L., Malachowski, J. and Baranowski, P. (2015) Optimization of protective panel for critical supporting elements. Composite Structures, 134, pp 493-505.

Mazurkiewicz, L., Malachowski, J., Damaziak, K., Baranowski, P. and Gotowicki, P. (2013) Identification of layers distribution in the composite coupon using finite element method and three point bending test. Acta Mechanica et Automatica, 7, 3, pp 160-165.

Pyka, D., Jamroziak, K., Blazejewski, W. and Bocian, M. (2017) Calculations with the finite element method during the design ballistic armour. In: Proc. 13th Int. Conf. on Computer Aided Engineering, (Rusinski, E. and Pietrusiak, D. eds). Springer International Publishing AG, pp 451-459.

Yahaya, R., Sapuan, S.M., Jawaid, M., Leman, Z. and Zainudin, E.S. (2016) Measurement of ballistic impact properties of woven kenaf-aramid hybrid composites. Measurement, 77, pp 335-343. 